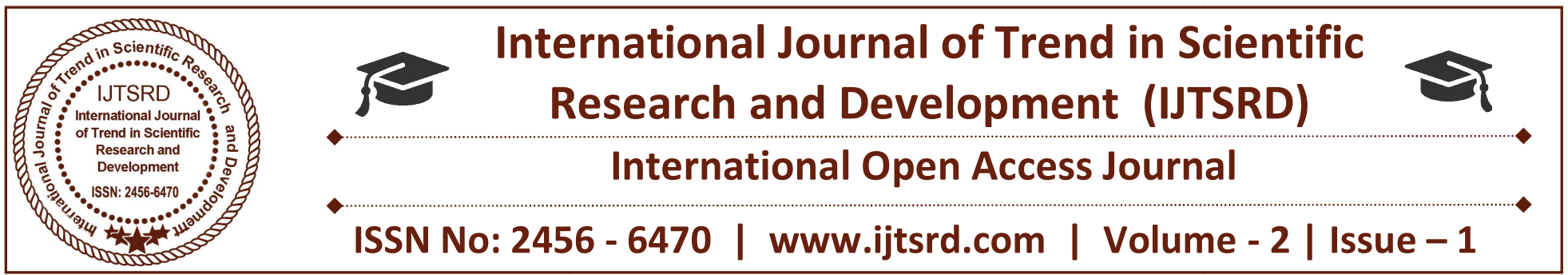

\title{
Simulation of 16 bit ALU using Verilog-hdl
}

\author{
Mr. Mayank Mittal \\ Student, Department of Electronics and Telecommunication, \\ Bhilai Institute of Technology Durg, Chhattisgarh
}

\begin{abstract}
In many digital circuits ALU is a basic building block. It can be used in integer arithmetic computations and as Complex operation. This research paper is based on the simulation of 16 bit ALU using VHDL. The design was implemented using VHDL Xilinx Synthesis tool ISE and targeted for Spartan device. An ALU performs following operations - Addition, subtraction, multiplication, Not, logical shift right, logical shift left, rotate right, rotate left, OR, AND, XOR, NAND, NOR, XNOR and comparison between two signals.
\end{abstract}

\section{INTRODUCTION}

An arithmetic logic unit (ALU) is a combinational digital electronic circuit that performs arithmetic and bitwise operations. It represents the fundamental building block of the central processing unit (CPU) of a computer. Modern CPUs contain very powerful and complex ALUs. An ALU performs basic arithmetic and logic operations. Examples of arithmetic operations are addition, subtraction, multiplication, and division. Examples of logic operations are NOT, AND, and OR. All operations perform in a computer is in form of binary number i.e. 0 or 1 . The logical operations are given below-

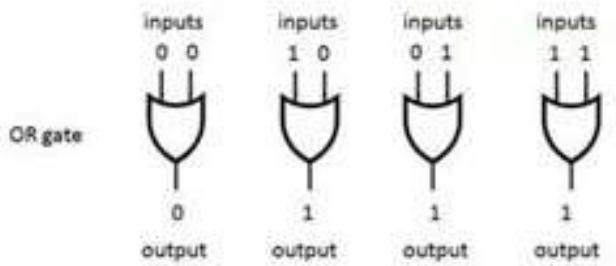

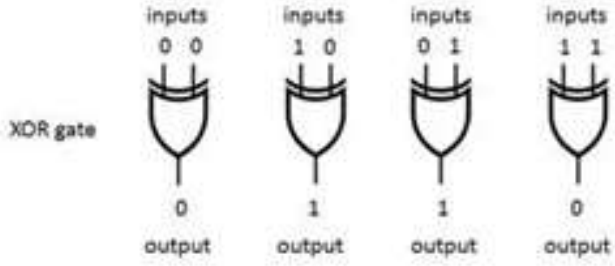

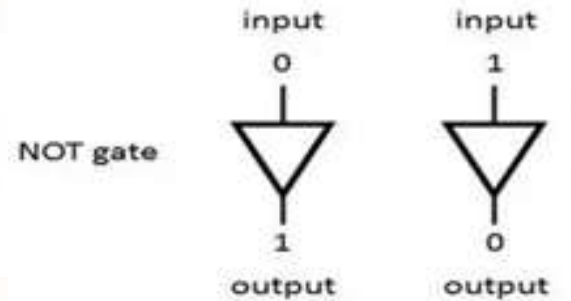

Table for different operation-

\begin{tabular}{|l|l|}
\hline Option & operation \\
\hline 0000 & Addition \\
\hline 0001 & Subtraction \\
\hline 0010 & Multiplication \\
\hline 0011 & Not \\
\hline 0100 & Logical shift left \\
\hline 0101 & Logical shift right \\
\hline 0110 & Rotate left \\
\hline
\end{tabular}

\begin{tabular}{|l|l|}
\hline 0111 & Rotate right \\
\hline 1000 & And \\
\hline 1001 & Or \\
\hline 1010 & Xor \\
\hline 1011 & Nor \\
\hline 1100 & Nand \\
\hline 1101 & xnor \\
\hline 1110 & Greater comparison \\
\hline 1111 & Equal comparison \\
\hline
\end{tabular}

Table 2.1 
International Journal of Trend in Scientific Research and Development (IJTSRD) ISSN: 2456-6470

\section{RTL schematic of ALU}

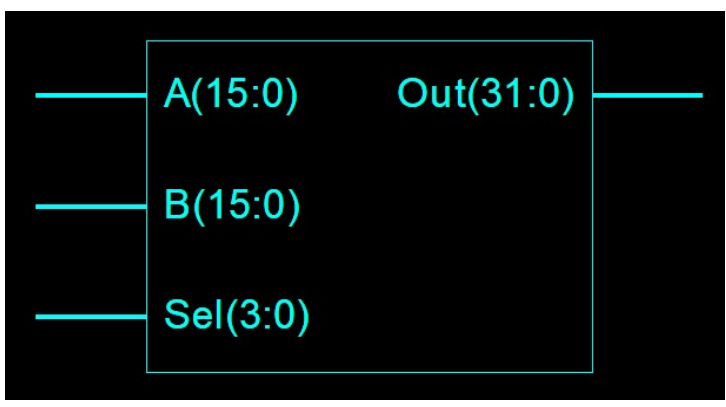

Figure: 2.1

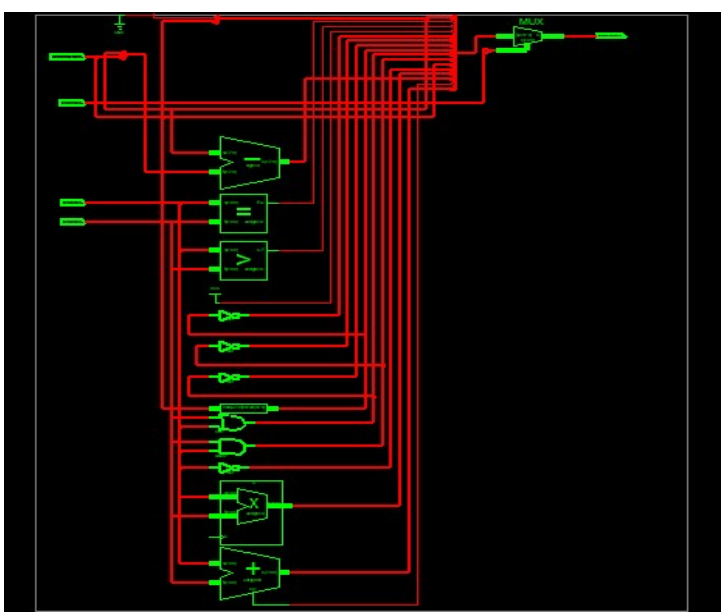

Figure: 2.2

\section{Result}

Verilog hdl implementation of ALU was done using Xilinx ise. Detailed report is given below in table no. 3.1 .

\begin{tabular}{|l|c|c|c|}
\hline Logic utilization & used & A vailable & utilization \\
\hline Number of Slices & 102 & 2448 & $4 \%$ \\
\hline $\begin{array}{l}\text { Number of 4 input } \\
\text { LUTs }\end{array}$ & 192 & 4896 & $3 \%$ \\
\hline $\begin{array}{l}\text { Number of bonded } \\
\text { IOBs }\end{array}$ & 68 & 108 & $62 \%$ \\
\hline $\begin{array}{l}\text { Number of } \\
\text { MULT18X18SIOs }\end{array}$ & 1 & 12 & $8 \%$ \\
\hline
\end{tabular}

Table: 3.1
The time delay and memory usage is given in table no. 3.2

\begin{tabular}{|c|c|}
\hline Delay & $12.339 \mathrm{~ns}$ \\
\hline Memory usage & 235436 kilobyte \\
\hline
\end{tabular}

\section{Table 3.2}

\section{CONCLUSION}

The simulation of 16 bit ALU is presented. This design is implemented using Verilog hdl and Xilinx ise and targeted for Spartan 3e family. The time delay is 12.339 ns and memory usage is 235436 kilobyte.

\section{REFERENCE}

1) Suchita Kamble, Prof .N. N. Mhala-VHDL Implementation of 8-Bit ALU IOSR Journal of Electronics and Communication Engineering (IOSRJECE) ISSN : 2278-2834 Volume 1, Issue 1 (May-June 2012), PP 07-11

2) Shikha Khurana , Kanika KaurIMPLEMENTATION OF ALU USING FPGA International Journal of Emerging Trends \& Technology in Computer Science (IJETTCS) Volume 1, Issue 2, July - August 2012 ISSN 2278-6856

3) Prakash R Tonse, Siddalingesh S. NavalgundDesign, Development and Implementation of ALU, RAM and ROM for 8051 Microcontroller on FPGA using VHDL International Journal of Computer Applications (0975 - 8887) Volume 80 - No1, October 2013 